\title{
CHANGES IN RETINAL ARTERIAL BLOOD PRESSURE DURING CYCLOPROPANE AND HALOTHANE ANAESTHESIA IN CHILDREN ${ }^{*}$
}

\author{
Oscar Farmati, M.D., Alfred Freeman, M.D., and Frank Moya, M.D. $\dagger$
}

OUR FIRST OPHTHALMODYNAMOMETRIC INVESTIGATION in children using halothane for anaesthesia showed a disproportionate decrease in the retinal arterial blood pressure when it was correlated with the brachial arterial blood pressure. The decrease was partially proportional to the depth of anaesthesia, which was monitored with the electroencephalograph. ${ }^{1}$

The purpose of this presentation will be to evaluate the effect of cyclopropane on the retinal arterial blood pressure, under similar investigational conditions.

The technique and principle of ophthalmodynamometry can be summarized as follows: The optic nerve and the central artery of the retina are visualized with the ophthalmoscope, and the ophthalmodynamometer is used to apply pressure over the lateral aspect of the eyeball. When the dynamometer raises the intraocular pressure to a level equal to the diastolic pressure in the ophthalmic artery, collapse of the central retinal artery occurs and expansile pulsations are seen because the blood then flows only during systole. When the intraocular pressure exceeds that of the systolic pressure in the retinal artery complete collapse of the vessel at the optic disc results. The eyeball, therefore, acts as a blood pressure cuff for measuring the pressure within the retinal arteries.

Laws concerning the flow of fluids in an elastic vessel show that at the point of compression the pressure will remain constant proximal to and reduced distal to the site of compression. Hence, the perfusion pressure in the ophthalmic artery itself is being measured rather than the retinal arterial pressure. ${ }^{2}$

The expansile pulsations must be carefully distinguished from the serpentine pulsations of the retinal vessels which may occur in cases of extremely low haematocrit, low peripheral resistance, large pulse pressure variations, and tortuosity of the arteries. ${ }^{3}$ Under normal conditions in a human subject, the systolic and diastolic retinal pressures are about half those of the systemic circulation, or slightly higher. ${ }^{2}$

\section{METHOD}

Children of physical status number 1 who required short surgical procedures were selected for this study because they were clinically free of artherosclerotic

'Supported in part by General Research Support Grant NIH-Inst. Fr. 5363-05/1390303.

†Dr. Farmati is Instructor of Anesthesiology, University of Pittsburgh School of Medicine, and Eye and Ear Hospital, Pittsburgh, $\mathrm{Pa}$. Dr. Freeman is Associate Professor of Anesthesiology, University of Miami School of Medicine, and Director, Department of Anesthesia, Variety Children's Hospital, Miami, Florida. Dr. Moya is Professor and Chairman, Department of Anesthesiology, University of Miami School of Medicine, and Jackson Memorial Hospital, Miami, Florida.

Can. Anaes. Soc. J., vol. 14, no. 1, January, 1967 
changes in the carotid circulation, exhibited no evidence of ocular or extraocular circulatory disorders, possessed normal scleral elasticity, and were in a state of good tissue hydration so that rapid refilling of the anterior chamber of the eye could be expected.

Fifteen children were studied using cyclopropane to maintain anaesthesia. The drugs and technique of preanaesthetic medication used depended upon the age of the patient and were identical with those used in a previous study of fifteen cases with halothane anaesthesia. ${ }^{1}$ Infants less than six months of age received atropine 0.15 to $0.2 \mathrm{mg}$. intramuscularly thirty minutes before the induction of anaesthesia.4 Infants between six months and one year of age received pentobarbital plus atropine intramuscularly approximately one hour before the induction of anaesthesia. The dosage schedule was as follows: pentobarbital $2 \mathrm{mg}$. per pound of body weight, plus atropine and meperidine $1 \mathrm{mg}$. per three pounds of body weight for those over one year of age..$^{5}$

The method of induction of anaesthesia was identical for all patients: Cyclopropane 40 per cent and oxygen 60 per cent were used by the to-and-fro bag and mask technique. Respiration was controlled as soon as possible. When plane three of stage three was reached, the trachea was intubated and anaesthesia was continued with adequate concentration of cyclopropane. Electroencephalographic needle electrodes were inserted into the scalp in the parietal and occipital areas, and the desired levels of anaesthesia were established. The criteria used for identifying the levels for cyclopropane were those suggested by Possati, Faulconer, and Bickford. ${ }^{6}$

Ophthalmodynamometric determinations were made and recorded as outlined previously, for each patient at E.E.G. levels I, I-II, II, II-III, III, IV with simultaneous measurements of intraocular tension using the Schiotz tonometer. In addition, systemic blood pressure, determined by auscultation over the brachial artery, and pulse rate were measured and recorded at the same E.E.G. levels and tabulated. End tidal $\mathrm{CO}_{2}$ was measured continuously using the ListonBecker LB-1 infrared $\mathrm{CO}_{2}$ analyser in all subjects.

As a means of evaluating the effect of the agent on retinal arterial blood pressure statistical analysis was used. The quantity $d=x-y$ was calculated for each patient at each of the six E.E.G. levels. Here $x=$ systemic pressure in $\mathrm{mm} . \mathrm{Hg}$ and $y=$ retinal pressure in $\mathrm{mm} . \mathrm{Hg}$. The systolic and diastolic pressures were each treated identically but separately in this way. An analysis of variance technique was applied separately to the differences, systemic minus retinal, for both systolic and diastolic pressures.

The rationale for employing the formula $d=x-y$ for analysis rests on the fact that the systemic and retinal pressures in the normal individual are highly correlated. The difference $x-y$ will in part remove or reduce this correlation. ${ }^{7}$

The correlation that is of concern here is that which exists between measurements taken on an individual. That is, as the systemic pressure increases, the retinal pressure will also tend to increase, and as the systemic pressure decreases the retinal pressure will also tend to decrease. The use of the differences between pressures will remove, insofar as possible, the effect of individual levels of pressure. 


\section{Results}

There were no significant changes in the pulse rate of any of the children during the period of study. Continuous infrared $\mathrm{CO}_{2}$ analysis indicated that the end tidal $\mathrm{CO}_{2}$ levels were within normal limits and remained constant throughout the investigation. In addition, evaluation by tonometry showed no significant changes in intraocular tension in any of the patients.

The mean changes in systemic arterial and retinal arterial blood pressure at the various E.E.G. levels, with cyclopropane anaesthesia, are presented in Figure 1. Although it is not indicated on the graph, the retinal arterial blood pressure returns to its original value as the anaesthesia is lightened.

In the analysis of the effect of the cyclopropane on the retinal arterial blood pressure we feel it is opportune to recall our results obtained in the investigation of halothane under similar conditions (Fig. 2). We wish to compare and contrast the effects of the two agents.
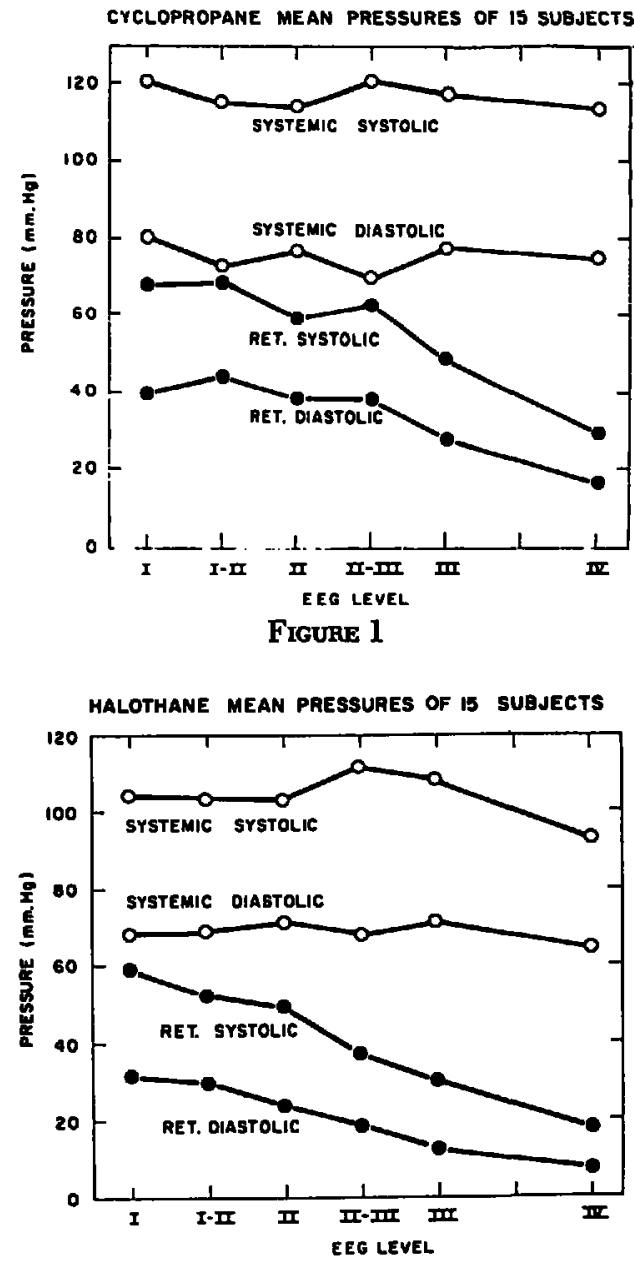

Figure 2 
The result of the analyses appears in Table I for systolic pressures and in Table II for diastolic pressures. In either case, the results are as follows (utilizing a $5 \%$ level of significance).

TABLE I

ANalysis of Variance of Differences of Systemic and Retinal Systolic Pressure in MM.Hg

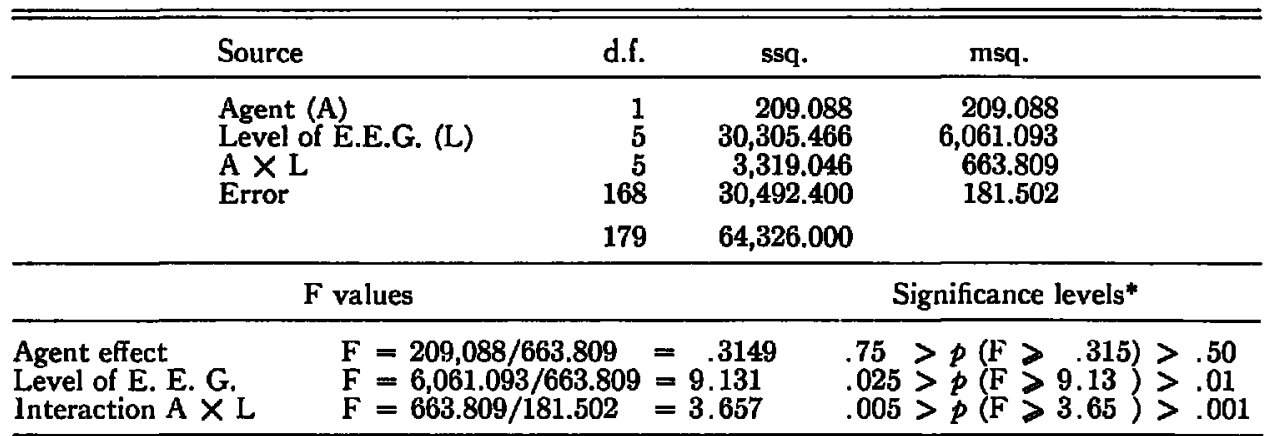

*The values in this column give bounds, upper and lower, for the probability that the $F$ statistic is as large as or larger than the calculated value, e.g., the probability that an $F$ value for 1 and 5 degrees of freedom is as large as or larger than .315 lies between .50 and .75 .

TABLE II

Analysis of Variance of Differences of Systemic and Retinal Diastolic Pressure IN MM.Hg

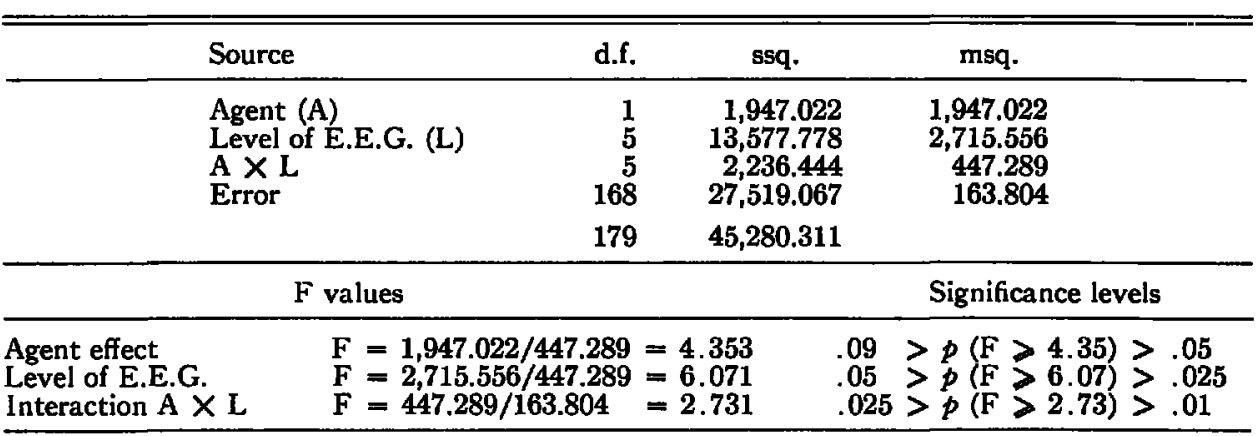

1. The two agents, halothane and cyclopropane, are not statistically different in terms of their average effect in lowering the retinal arterial blood pressure (ignoring levels of E.E.G.).

2. The six levels of E.E.G. differ more than can be accounted for on the basis of chance alone.

3. There is a significant interaction between agent and levels of E.E.G. That is to say, although the two agents can be considered similar in their average effect, the "progression" by which this average effect is achieved differs. This fact is most strikingly observed in Tables III and IV, where means of the values $d=x-y$ appear for each level of E.E.G. and for each agent. 
TABLE III

Means of Differences of Systemic Minus Retinal Systolic Pressure in mu.Hg FOR EACH AGENT AND LEvel OF E.E.G.*

\begin{tabular}{lcccccc}
\hline \hline & \multicolumn{7}{c}{ Level of E.E.G. } \\
\cline { 2 - 7 } & I & I-II & II & II-III & III & IV \\
\hline Halothane & 45.13 & 51.67 & 54.00 & $\mathbf{7 4 . 3 3}$ & $\mathbf{7 9 . 0 0}$ & $\mathbf{7 6 . 3 3}$ \\
Cyclopropane & $\mathbf{4 8 . 0 0}$ & $\mathbf{4 7 . 3 3}$ & $\mathbf{5 6 . 0 7}$ & $\mathbf{5 9 . 1 3}$ & $\mathbf{6 9 . 6 7}$ & $\mathbf{8 7 . 3 3}$ \\
\hline
\end{tabular}

*Based on 15 patients at each level, using a difference of systemic minus retinal pressure in $\mathrm{mm} . \mathrm{Hg}$, the means were determined as follows: mean $=\left[\left(x_{1}-y_{1}\right)+\left(x_{2}-y_{2}\right)+\left(x_{8}-y_{8}\right)+\ldots+\left(x_{15}-y_{16}\right)\right] / 15$ $x=$ systemic pressure for the individual patients.

The subscripts $1,2, \ldots 15$ denote individual patients.

TABLE IV

Means of Differences of Systemic Minus Retinal Diastolic Pressure in Mm.Hg For Each Agent and Level of E.E.G."

\begin{tabular}{lcccccc}
\hline \hline & \multicolumn{7}{c}{ Level of E.E.G. } \\
\cline { 2 - 7 } & I & I-II & II & II-III & III & IV \\
\hline Halothane & 37.20 & 38.87 & $\mathbf{4 6 . 6 7}$ & 49.33 & 58.67 & $\mathbf{5 6 . 7 3}$ \\
Cyclopropane & 40.33 & $\mathbf{2 7 . 3 3}$ & 38.67 & 32.67 & $\mathbf{5 0 . 3 3}$ & 58.67 \\
\hline
\end{tabular}

*Means deternined as in Table III.

\section{Comment}

It is recognized that the electrical activity of the brain is dependent on many parameters, all of which may vary independently. With the maintenance of high $\mathrm{O}_{2}$ tension in the inspired gases, maintenance of body temperature at normothermic levels, avoidance of hypotension, and maintenance of normal alveolar $\mathrm{CO}_{2}$ levels, the E.E.G. has been considered a reliable method of determining the depth of anaesthesia. ${ }^{8,0}$

However, the reliability of dynamometric readings is limited by certain factors. It was observed that in abnormal changes in intracranial pressure, the dynamics of the cerebrospinal fluid, and the viscosity of the blood, may influence the dynamometric readings. It must also be recognized that excessive scleral rigidity, refraction difficulties, slow replacement of the aqueous fluid expelled during the compression of the globe, and the fatigue of the observer may introduce error. The ophthalmodynamometric readings are not absolute measurements but are useful for comparative purposes. ${ }^{2,3}$

The central retinal artery may indicate the cerebral circulation, since it is a terminal branch of the internal carotid artery. Some of the properties common to both the retinal and the cerebral circulations are their identical physiologic responses to $\mathrm{CO}_{2}$ changes and their state of tonic dilatation. ${ }^{3}$

The autonomic nervous system plays a relatively minor role in the control of the tone of these vessels in man, and human subjects present definite insensi- 
tivity to neurogenic vasoconstrictor reflexes and vasopressor substances. ${ }^{10}$ The retinal and cerebral vascular reactivity are also correlated in normal and arteriosclerotic individuals. ${ }^{11}$

At the present time it is reasonable to assume that a progressive decrease of the cardiac contractility, occurring earlier with halothane than with cyclopropane, ${ }^{12,13}$ can cause a drop in the blood pressure in the central retinal artery due to the lack of compensatory vasoconstriction in its distribution. We also should consider the direct cerebral vasodilator effect of halothane. ${ }^{12}$

The situation is not similar in the vessels of the limbs, where a delay in the release of the vasoconstrictor tone (i.e. with halothane) or a positive response to the circulating catecholamines (i.e. with cyclopropane ${ }^{12}$ ) enables us to maintain a "normal" brachial arterial blood pressure reading under "adequate" anaesthesia.

Further investigation with cyclopropane is suggested for a more definite interpretation of our findings in the human subject.

\section{SUMMARY}

Ophthalmodynamometric determinations were used for measuring the blood pressure in the central retinal artery during cyclopropane anaesthesia in children. The results were correlated with the systemic blood pressure and later analysed and compared with the results obtained under similar conditions when the maintenance agent was halothane. When evaluated in terms of the difference between systemic and retinal arterial pressures, both systolic and diastolic, the two agents were shown to have similar average effects, i.e. in lowering the retinal arterial blood pressure. It is the progression of the blood pressure change over the various E.E.G. levels which distinguishes the two agents.

\section{RÉSUMÉ}

Nous avons employé les déterminations ophtalmodynamométriques pour mesurer la pression sanguine dans l'artère rétinienne centrale au cours de l'anesthésie au cyclopropane chez les enfants. La diminution da la pression sanguine dans l'artère rétinienne était proportionnelle à la profondeur de l'anesthésie évaluée par l'électro-encéphalogramme. Les résultats correspondaient à la pression sanguine systémique. Les effets du cyclopropane ont également été comparés à ceux de l'halothane dans des conditions semblables.

Nous nous sommes servis d'une étude statistique, en employant une analyse des variantes techniques, pour évaluer l'effet des agents sur la pression sanguine artérielle rétinienne. La quantité $d=x-y$ a été calculée pour chaque malade à chacune des six niveaux de l'électroencéphalogramme. La raison pour justifier l'emploi de $d=x-y$ pour l'analyse repose sur le fait que les pressions systémique et rétinienne chez l'individu non anesthésié sont tout à fait les mêmes.

L'analyse a démontré que les deux agents: le cyclopropane et l'halothane ont des effets moyens semblables en diminuant la pression sanguine de l'artère rétinienne. C'est la progression de ces différences sur les niveaux variés de l'E.E.G. qui distingue les deux agents. 
Nous sommes enclins à penser qu'une diminution de la force de contractilité du myocarde survient plus précocement avec l'halothane qu'avec le cyclopropane et qu'elle serait la cause d'une chute de la pression sanguine dans l'artère rétinienne à cause du manque de vasoconstriction compensatrice à cet endroit.

\section{ACKNOWLEDGMENT}

The authors wish to thank Floyd H. Taylor, Sc.D., Assistant Professor of Preventive Medicine at the School of Medicine, University of Pittsburgh, for his assistance with the statistical analysis.

\section{REFERENCES}

1. Farmati, O.; Freeman, A.; \& Moya, F. Measurement of Retinal Artery Blood Pressure during Anesthesia in Children. South. M.I. (In press.)

2. Duke-Elden, S. System of Ophthalmology. 1st ed., vol. 7, St. Louis: Mosby (1963), pp. 355-362.

3. AdLer, F. Physiology of the Eye: Clinical Application. 3rd ed., St. Louis: Mosby (1959), pp. $272-309$.

4. Bachman, L. \& Freeman, A. The Cardiac Rate and Rhythm in Infants during Induction of Anesthesia with Cyclopropane: Stropine versus Scopolamine as Preanesthetic Medication. J. Pediat. 59: 922 (1961).

5. Fremman, A. \& Bachman, L. An Evaluation of Methods of Premedication in Children. Anesth. \& Analg. 38: 424 (1959).

6. Possati, S.; Faulconer, A., Jr.; Bickford, R. S.; \& Hunter, R. C. Electroencephalographic Patterns during Anesthesia with Cyclopropane: Correlation with Concentration of Cyclopropane in Arterial Blood. Anesth. \& Analg. 32: 130 (1953).

7. Brownlez, K. A. Statistical Theory and Methodology in Science and Engineering. 1st ed., New York: Wiley (1960), pp. 383-386.

8. MARTIN, John T.; Faulconer, A., JR.; \& BICKFord, R. Electroencephalography in Anesthesiology. Anesthesiology. 20: 359 (1959).

9. Brechner, V. L. Current Status of Electroencephalography in the Practice of Clinical Anesthesia. Clinical Anesthesia: Instrumentation and Anesthesia. 2nd ed., Philadelphia: Davis (1964), pp. 88-106.

10. Best, C. H. \& Tayzon, N. B. Physiological Basis of Medical Practice. 7 th ed., Baltimore: Williams Wilkins (1961), pp. 205-231, 343.

11. Hickam, J. B.; Scrmeve, J. F.; \& Wrison, W. P. The Relation between Retinal and Cerebral Vascular Reactivity in Normal and Arteriosclerotic Subjects. Circulation. 7: 84 ( 1953).

12. Price, H. L. \& Conen, P. Effects of Anesthetics on the Circulation. 1st ed., Springfield: Thomas (1964), pp. 70-73, 209-214, 278-283.

13. Fabian, L. W. Anesthesia and the Circulation. Clinical Anesthesia. 1st ed., Philadelphia: Davis (1964), pp. 56-77. 